\title{
All provinces can now sue big tobacco
}

$\mathrm{N}$ a Scotia has officially become the last province in Canada to proclaim legislation giving it the legal green light to sue tobacco companies for unlawful activities alleged to increase smoking rates. Minister of Health and Wellness Leo Glavine says the Tobacco Damages and Health-care Costs Recovery Act will enable the province to hold the tobacco industry accountable "for fraud, deception and conspiracy that led to addiction and illness among Nova Scotians."

The province has joined British Columbia, Saskatchewan, Manitoba, New Brunswick and Prince Edward Island to bring collective action against at least three tobacco companies Imperial Tobacco Canada, Rothmans, Benson \& Hedges and JTI-MacDonald Corp. - for actions dating back to the 1950s in some cases. Many of those provinces have already filed statements of claim with the courts. Nova Scotia expects to do so by the end of the year.

There is power and efficiency in numbers, says Dr. Robert Strang, Nova Scotia's chief public health officer. "There is a huge amount of work to collect documents and data to support the claim that there have been health care costs generated by the tobacco industry."

That work began in BC in 1998, when it became the first jurisdiction in Canada and the British Commonwealth to pass legislation enabling it to sue tobacco companies. The fight remains a priority, according to a spokesperson from the BC Ministry of Health.

$\mathrm{BC}$ 's inaugural legislation, and other acts that flowed from it, point to the tobacco manufacturers' breach of duty, such as failure to warn and misrepresentation. The provinces are also asserting that tobacco manufacturers are marketing "light" cigarettes as safer when they knew they were not, targeting children in their advertising

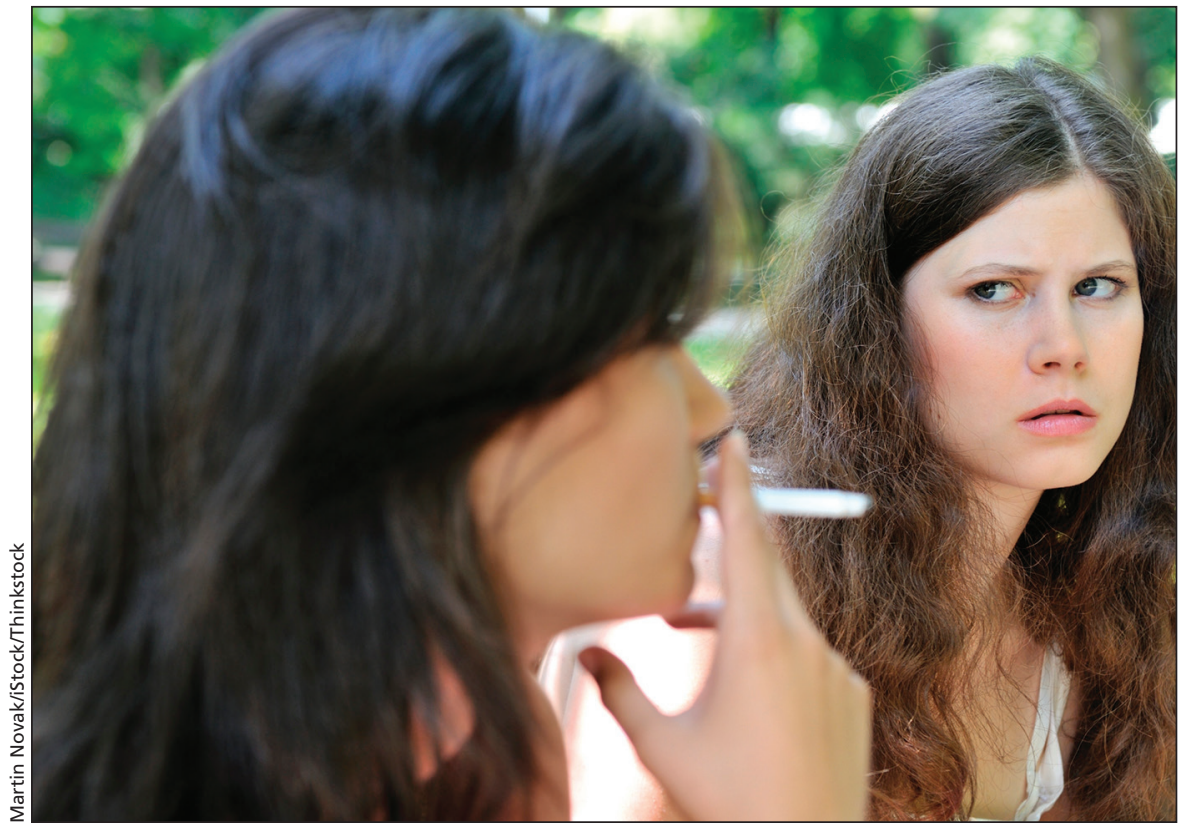

The new legislation will hold the tobacco industry accountable "for fraud, deception and conspiracy that led to addiction and illness among Nova Scotians."

and conspiring to suppress research on the risks of smoking.

While the health risks of smoking have been well documented for decades — in Nova Scotia, more than 1700 people die each year from smokingrelated illness and 200 more die from exposure to second-hand smoke - this is not sufficient for a verdict of "guilty." "This is not an epidemiological debate," says Strang. "We need to prove this in a court of law."

"The evidence is solid that using tobacco creates health problems, but the case is that the tobacco companies continued to promote their products knowing this evidence," he adds.

Proving this has been time consuming. BC's original legislation was successfully challenged by the tobacco companies and had to be rewritten. Currently, the province is engaged in trial preparation, but a trial date has not yet been set.
Ontario is also preparing for court. "In 2009, we launched a $\$ 50$ billion action against the domestic manufacturers of tobacco products and their foreign parents," says Brendan Crawley, spokesperson for the Ontario Ministry of the Attorney General.

In May 2013, the Court of Appeal for Ontario dismissed a motion brought by six foreign tobacco companies challenging Ontario's jurisdiction over them. Seven months later, the Supreme Court of Canada refused to grant leave to the tobacco companies to appeal that decision.

Strang is hopeful that the legal wrangling will conclude in his lifetime, but there is no immediate end in sight. "It will be years if not decades before this is resolved," he says. "The tobacco companies will find ways to slow this down." — donalee Moulton, Halifax, NB

CMAJ 2014. DOI:10.1503/cmaj.109-4929 